In Stelle beg mit bem 1. Dftober in Rutheftanb tretenben bistịerigen Direftors ber Forfatabemie Eifena山, Dkerlandforfmeiffere Dr. Stöks, wito Zorftrat Matthe so bortjelbyt treter.

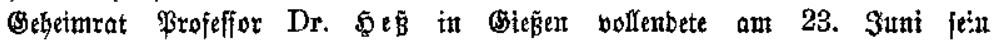

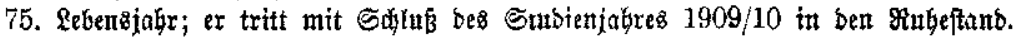

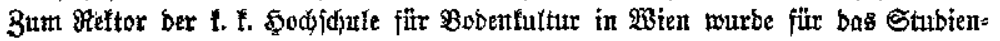

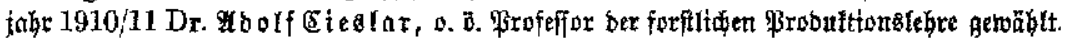

Der Frivatbozent fïr Bobenfunbe unb Agrifulturdyemie Dr. Maximilian

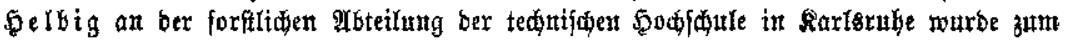

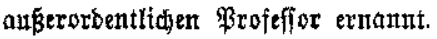

\title{
Drulfehler $=$ Berintitgung.
}

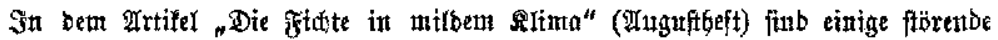
Brudfehler fteben geblieben:

S. 435 3. 1 v. o. "1unger" ftatt Heiger,

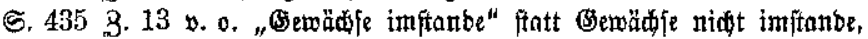

5. 447 3. 3 v. น. "mittelaIte" fiatt mittelalterlicte,

S. 448 3. 7 v. D. "Dffertifuttide" fitat iffentlide,

5. 449 in ber Inkelle "Befannt" jîtt beftimmt,

S. 450 3. 3 ๖. v. "erfreulidies" pratt etbonfitues.

\section{Antetigen.}

Dorlefungen an forftlidien Eqodifłulen im Winterfemefiter 1910/11.

Univerfität Gię̧en.

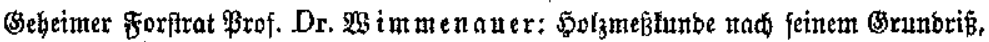

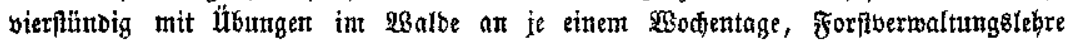

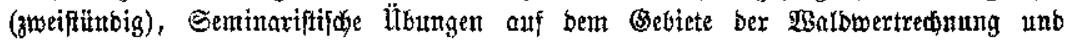
Forffftatif (einftüntig), Inleitung zum \$ianzeidnen (zbeiftünoig). \$rof. Dr. פBeber:

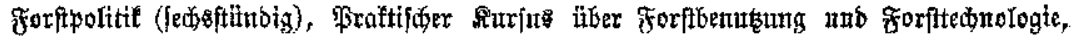
etrtmal mödentlid.

Beginn Der Smmatrifuration: 17. Dftober. Begitn ber \$2orfejungen: 24. Dftober.

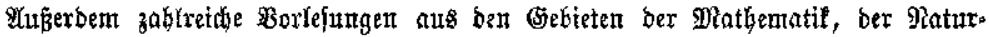

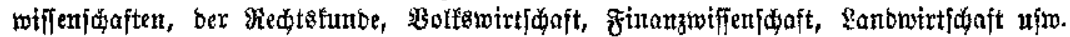

Das allgemeine Borlefunggoerzetuniz fann son bem Univerfitätofeftretariat untent= gettlich bezogen werben.

\section{Utniberfität Tübingen.}

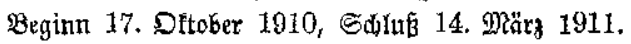

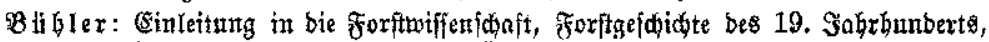

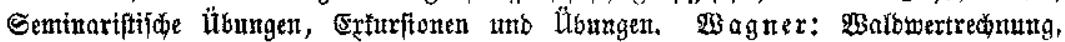

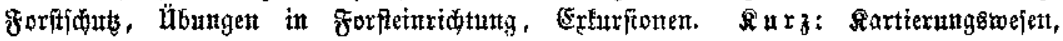

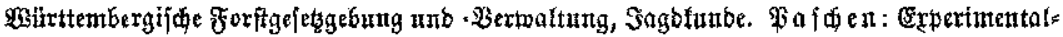
phylte. Wa

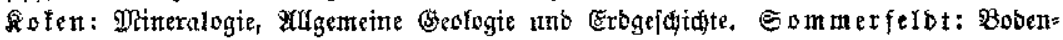

